\title{
Professoras Transexuais e Travestis no Contexto Escolar: entre estabelecidos e outsiders
}

\author{
Marco Antônio Torres' \\ Marco Aurélio Prado" \\ 'Universidade Federal de Ouro Preto (UFOP), Ouro Preto/MG - Brasil \\ "Universidade Federal de Minas Gerais (UFMG), Belo Horizonte/MG - Brasil
}

RESUMO - Professoras Transexuais e Travestis no Contexto Escolar: entre estabelecidos e outsiders. Neste artigo debatemos questões envolvidas na emergência de professoras transexuais femininas ou travestis na escola. Utilizamos a noção de outsiders e de heteronormatividade para analisar como essas professoras permanecem na função docente. Consideramos que a emergência dessas professoras está relacionada a novos posicionamentos referentes às noções de gênero nas políticas de direitos humanos, especificamente pelas lutas do movimento social. Por fim, afirmamos que a emergência dessas professoras não pode ser compreendida como suspensão da heteronormatividade, mas como o aparecimento de novas questões para se analisar no ambiente escolar.

Palavras-chave: Educação. Professoras. Transexualidades. Heteronormatividade.

\begin{abstract}
Transgender and Transvestite Teachers in the School Context: between established and outsiders. This paper analyzes social aspects involved in the emergence of transgender (male-to-female) teachers at school. We use the notions of outsiders and heteronormativity to analyze how these teachers remain in the teaching profession. We believe that the emergence of such teachers is related to new positions relative to notions of gender in human rights policies, specifically the struggles of social movements. Finally, we argue that the emergence of these teachers cannot be understood as suspension of heteronormativity, but as the emergence of new issues to consider in the school environment.

Keywords: Education. Teachers. Transgender. Heteronormativity.
\end{abstract}

Educação \& Realidade, Porto Alegre, v. 39, n. 1, p. 201-220, jan./mar. 2014.

Disponível em: <http://www.ufrgs.br/edu_realidade> 


\section{Travestis, Transexuais e Outros Outsiders na Escola}

Neste artigo elaboramos um recorte específico acerca de algumas experiências de professoras que se autodefinem como transexuais femininas e travestis. Analisamos algumas estratégias utilizadas por essas professoras com aqueles/as que a constituem, na maioria das vezes, como outsiders no ambiente escolar. A partir de determinados autores (Bento, 2006; Butler, 1999), consideramos transexuais femininas aqueles sujeitos designados como masculinos no nascimento e que ao longo da vida entraram em conflito com essa designação; também são denominados como mulheres transexuais, mulheres trans, entre outros termos similares. Termos como transexual masculino, ou homem trans, são autodefinições e formas de reconhecimento de sujeitos designados como femininos no nascimento e que se constituem como masculinos durante a vida. Travesti é uma categoria identitária específica (Pelúcio, 2009; Benedetti, 2005) que se refere a sujeitos que entram em conflito com a designação de homens atribuída no nascimento, semelhante a transexuais (masculinos e femininos), e possui nuanças específicas, como veremos adiante.

Essas especificações não são frequentes no senso comum, porém têm sido pautadas por coletivos de lésbicas, gays, bissexuais, travestis e transexuais $(\mathrm{LGBT})^{1}$. De diferentes modos, todas essas formas de vida podem se constituir como alvos da homofobia, ou seja, de comportamentos e concepções elaborados na produção da cultura e dos saberes ocidentais que aparecem na discriminação afetiva, intelectual e política por lógicas heterossexistas (Borrillo, 2010), entre outras. Essas lógicas produzem relações em que hierarquias baseadas no sexo-gênero constituem LGBT, entre outras formas de vida, também como outsiders, ou seja, produzem nas interdependências sociais sujeitos considerados humanamente inferiores e alvos de ódio e violências (Elias; Scotson, 2000). Preferimos o termo outsider à noção de abjeto em Butler (1999), por considerá-lo mais específico para descrever as dinâmicas relacionais entre sujeitos humanos, especialmente pelo seu histórico nos debates propostos a partir da Psicologia Social.

A questão seminal deste artigo foi formulada em 2009, durante uma pesquisa realizada entre 2008-2012, quando encontramos algumas professoras que se definiam como mulheres transexuais e/ou travestis. A pergunta que emergiu naquele momento foi: como transexuais femininas ou travestis se mantêm na função de professoras em um contexto marcado pela homofobia? Para nossas análises, organizamos dois corpora empíricos; também realizamos observações em encontros de coletivos LGBT e outros específicos de travestis e transexuais. Nas observações, notamos a importância que alguns documentos ganhavam nos debates desses coletivos e selecionamos dois que consideramos importantes. Estes pautavam demandas específicas de travestis e transexuais, como aquelas relacionadas ao uso do nome social, ao acesso a 
direitos básicos, à assistência do Sistema Único de Saúde para realização de alterações corporais e uso de hormônios etc. Assim, o primeiro corpus foi formado por dois documentos das políticas de direitos humanos - Princípios de Yogyakarta (Corrêa; Muntarbhorn, 2006) e o Plano Nacional de Promoção da Cidadania e Direitos Humanos LGBT (Brasil, 2009) -, e o segundo foi constituído por entrevistas com sete professoras que se autodefiniam como travestis e/ou transexuais femininas. Utilizamos algumas vezes o condicional e/ou porque algumas se classificavam como travestis e como mulheres transexuais ao mesmo tempo. Apenas a professora 2 se assumiu exclusivamente como travesti, três se definiram como mulheres transexuais e outras três alternaram entre as transexualidades e as travestilidades; isto indica que a singularidade das experiências dos sujeitos exige pensar as categorias no plural. Todavia, percebemos que aquelas que participavam de coletivos do movimento social de LGBT mais bem delimitavam o uso dos termos travesti e transexual; com isso, podemos entender que existe um processo em curso de apropriação semântica dessas noções pelos sujeitos (Barbosa, 2010), conforme será especificado mais adiante.

Em uma observação que fizemos em fevereiro de 2012, na cidade de Belo Horizonte, no $1^{\circ}$ Encontro Nacional da Rede Trans Educ, grupo constituído por educadores/as transexuais e travestis, já havia alguns sujeitos que se autodefiniam como professores transexuais masculinos. Contudo não tivemos contatos mais próximos com eles naquela ocasião. Privilegiamos aqui o estudo sobre mulheres trans, uma vez que já existia o grupo organizado da rede que naquele momento era por nós observado. A Rede Trans Educ até fevereiro de 2012 havia localizado 51 profissionais da educação, predominantemente travestis e/ou transexuais femininas. Podemos supor que esta questão esteja relacionada à maior presença das mulheres na profissão docente (Louro, 1997), revelando um processo de feminização do perfil, porém não aprofundaremos tal temática neste artigo. A seguir, localizaremos algumas categorias que norteiam nosso debate no campo de pesquisa.

Inicialmente, vejamos o conceito de heteronormatividade, segundo Miskolci (2009), o qual foi proposto em 1991, por Michael Warner, num contexto em que alguns autores retomavam a noção de sexualidade elaborada por Michel Foucault. Aqui entendemos a heteronormatividade como "[...] um conjunto de prescrições que fundamenta processos sociais de regulação e controle" (Miskolci, 2009, p. 156), em que predominam discursos nos quais reprodução e heterossexualidade se associam à ideia de família. Por fim, podemos compreender que a transfobia e seus correlatos funcionam como dispositivos dinâmicos da heteronormatividade, provocando prejuízos a toda educação (Ramires, 2011; Prado; Junqueira, 2011), pois esses dispositivos, ao produzirem as relações sociais, o fazem estabelecendo hierarquias em que LGBT, entre outros, são definidos em processos de subalternização, tendo menos acesso e reconhecimento. Pesquisas recentes revelam que, entre 
outros, o preconceito contra homossexuais (FIPE; INEP; MEC, 2009) e a homofobia (Díaz; Chinaglia; Díaz, 2011) no ambiente escolar estão relacionados respectivamente ao baixo rendimento na educação e a violência no contexto escolar.

Também no contexto da década de 1990, Judith Butler (1999) elabora uma análise crítica a partir da noção de gênero e propõe as normas de gênero como construtos discursivos que buscam a regulação dos corpos pelo privilégio do masculino, pelo dimorfismo sexual e pela heterossexualidade compulsória. Posteriormente, Butler (2006) retoma suas elaborações a partir de críticas recebidas e aprofunda a noção de instabilidade dessas normas, analisando como as formas de vida de Drag Queens e Drag Kings, transexuais, crossdressers, entre outras, indicam a contingência do gênero. O conceito de heteronormatividade é articulado à definição de normas de gênero para analisar a reiteração cotidiana da heterossexualidade como verdade para os corpos nos currículos e conteúdos escolares (Lionço; Diniz, 2009; Louro, 2009; Junqueira, 2009).

No movimento LGBT brasileiro, com posições mais identitárias, existe uma busca de especificação do termo homofobia; assim têm sido utilizados os termos lesbofobia, homofobia, bifobia e transfobia. Discriminar analiticamente o termo transfobia até pode ser um modo do reconhecimento político das travestilidades e transexualidades para demarcar um lugar no movimento LGBT e em outros contextos (Carvalho, 2011). Contudo, apesar da polissemia terminológica, ainda que necessária nas políticas públicas, nós queremos atentar para aquilo que consideramos fundamental nestes debates: elaborar análises que questionem a naturalização das normas de gênero na cultura (Butler, 2006), tendo em conta a heteronormatividade como um conjunto de princípios organizados por essas normas (Miskolci, 2009).

Desse modo, travestis e transexuais, entre outros que se constituem em conflito com as normas de gênero, em diferentes contextos podem ser tomados como outsiders. Esse termo foi elaborado por Norbert Elias quando ele se associou a John Scotson (Elias; Scotson, 2000), que inicialmente pretendia investigar a delinquência juvenil em uma pequena localidade inglesa. Esses autores identificaram um fenômeno naquela localidade, isto é, a atribuição de valores a alguns membros da comunidade e a constituição de estigmas que eram atribuídos a outros, algo que eles definiram como uma figuração do tipo estabelecidosoutsiders. O conceito de figuração ou configuração utilizado é de Elias (1970) e diz de relações que se estabelecem entre seres humanos nos mais variados níveis das relações humanas, seja em pequenos grupos, em países ou mesmo em contextos internacionais. Assim, Elias e Scotson (2000) analisaram como, nas interdependências sociais, se constituíam grupos que, cadenciados por dinâmicas relacionais específicas, estabeleciam modos de relacionamento que definiam alguns pela desclassificação e outros pela superioridade, respectivamente outsiders e estabelecidos. 
[...] o grupo estabelecido atribuía a seus membros características humanas superiores; excluía todos os membros do outro grupo de contato social não profissional com seus próprios membros [...] Assim, a exclusão e a estigmatização dos outsiders pelo grupo estabelecido eram armas poderosas para que este último preservasse sua identidade e afirmasse sua superioridade, mantendo os outros firmemente em seu lugar (Elias; Scotson, 2000, p. 20-22).

Essa suposta superioridade humana de uns sobre os outros e o diferencial de poder e a submissão inelutável em relação aos outsiders fazem com que estes vivenciem "[...] afetivamente sua inferioridade de poder como um sinal de inferioridade humana” (Elias; Scotson, 2000, p. 28). Todavia, à medida que esses diferenciais de poder sofrem alterações, essas dinâmicas podem se modificar, assim nenhum dos grupos indica uma condição permanente. Analisamos que nas dinâmicas sociais envolvendo LGBT existe uma subalternização não apenas desprezada socialmente, mas perseguida e muitas vezes eliminada, como demonstram os levantamentos de assassinatos de LGBT (Mott; Almeida; Cerqueira, 2011), entre os quais temos subsumidas as travestis e transexuais. Pesquisadores afirmam que, no caso dos assassinados, “[...] o fato de ser travesti parece ser o fator determinante da execução - que assume as feições de um crime de ódio” (Carrara; Vianna, 2006, p. 245). Esses pesquisadores ainda consideram que as travestis, como profissionais do sexo, tornam-se vítimas mais vulneráveis, marcadas pela pobreza, pelo desprezo policial na averiguação do crime; enfim, sua condição é marcada pela possibilidade de se tornar mais um corpo estendido no chão, para usar o título do artigo citado. Todavia, temos assistido uma busca de articulações políticas para o enfrentamento da discriminação e da violência que tem ocorrido em âmbito nacional e internacional. Essa articulação tem resultado em várias ações e posições políticas, uma delas pode ser vista nos Princípios de Yogyakarta (daqui por diante, PY), documento preparado em novembro de 2006, na Indonésia, encaminhado às Nações Unidas, cuja proposta define duas categorias analíticas importantes nas pesquisas: orientação sexual e identidade de gênero:

COMPREENDENDO orientação sexual como estando referida à capacidade de cada pessoa de experimentar uma profunda atração emocional, afetiva ou sexual por indivíduos de gênero diferente, do mesmo gênero ou de mais de um gênero, assim como de ter relações íntimas e sexuais com essas pessoas; ENTENDENDO ídentidade de gênero como estando referida à experiência interna, individual e profundamente sentida que cada pessoa tem em relação ao gênero, que pode, ou não, corresponder ao sexo atribuído no nascimento, incluindo-se aí o sentimento pessoal do corpo (que pode envolver, por livre escolha, modificação da aparência ou função corporal por meios médicos, cirúrgicos ou outros) e outras expressões de gênero, inclusive o modo de vestir-se, o modo de falar e maneirismos (Corrêa; Muntarbhorn, 2006, p. 9).

Educação \& Realidade, Porto Alegre, v. 39, n. 1, p. 201-220, jan./mar. 2014.

Disponível em: <http://www.ufrgs.br/edu_realidade> 
Consideramos a emergência das categorias orientação sexual e identidade de gênero indicadora da possibilidade de alterações na balança de poder na figuração estabelecidos-outsiders. Os significados atribuídos àquelas categorias pelas professoras travestis e transexuais podem explicitar muito mais do que suas preferências singulares; referem-se à história das des/identificações desses sujeitos. Também a utilização desses termos diz das tentativas dos sujeitos em acessar uma semântica para o reconhecimento (Honneth, 2003), ainda que de modo binário. Segundo Axel Honneth, os movimentos sociais podem fornecer aos sujeitos significados que ganham inteligibilidade pública e possibilidade de inclusão social. Assim, a apropriação das noções de identidade de gênero e orientação sexual por LGBT na escola pode indicar a importância dos PY nas disputas entre estabelecidos e outsiders.

Na escola, a presença das professoras travestis e transexuais pode indicar alterações na balança do poder entre elas e os outros sujeitos num contexto em que a heteronormatividade delimita o campo da educação. Podemos considerar que os estabelecidos se constituem quando alguns questionam a possibilidade de elas exercerem a função docente, recusam reconhecer o nome social, evitam socialmente as professoras travestis e transexuais, entre outras questões. Vejamos um pouco dos modos como o poder, compreendido como relações de interdependência entre os outsiders e os estabelecidos, aparece na escola, especificamente em relação a uma professora transexual. Vejamos, segundo a entrevista com a professora 2, como nas dinâmicas inter-relacionais podem ocorrer modificações em relação aos outsiders.

Acho que num primeiro momento há sim uma repulsa, não só o fato de ser gay, que a gente verifica na presença de alguns colegas também militantes, dos profissionais que trabalham com a gente que são gays. Tanto lésbicas como meninos homossexuais, mas o travesti ainda parece que agrava mais. Porém eu acho que é só em um primeiro momento, quando você passa segurança para o grupo, quando você mostra que você é só mais um ser humano, a questão do contato se torna normal e a formação hoje proporciona muito isso no nosso Estado. Quando você termina a formação, as professoras e professores vêm te abraçar, vêm te beijar. Num primeiro momento, onde geralmente o professor do sexo masculino ele te cumprimenta com um apertão de mão que quase quebra sua unha, no final ele já vem e já beija seu rosto, já pede seu telefone, mantém contato como profissional. Assim, esse afeto ele vai sendo construído, acho que da mesma maneira que se constroem os outros momentos afetivos de qualquer outro grupo, claro que com a travesti é mais complicado, nós vamos ter este ou aquele que vai ser mais resistente, esse ou aquele que vai achar que aquilo que você está falando é uma aberração, mas na maioria você tem os $70 \%$ que reveem suas posturas, vê que não é um bicho de sete cabeças, é um bicho só de duas cabeças (Professora 2, 84, 2010)².

Esses posicionamentos de participantes do contexto escolar em relação às professoras, entrevistadas em nossa pesquisa, provocam debates e disputas que colocam em análise várias questões, entre as quais podemos citar o estigma produzido no ambiente escolar para professo- 
res/as que se afastam da norma heterossexual e o enfrentamento, por professores/as LGBT, da heteronormatividade presente na educação (Franco, 2009; Junqueira, 2009). Em todas as entrevistas também havia relatos de relações de apoio e solidariedade, principalmente por parte do alunado. Esses posicionamentos de sujeitos em relação às professoras transexuais femininas e travestis propiciam análises dos mecanismos sutis e perversos de poder para subalternização desses sujeitos no ambiente escolar, bem como suas estratégias para o enfrentamento às formas de negação da possibilidade de as entrevistadas se manterem na função docente. Nessas dinâmicas, podemos compreender alterações nas relações de poder entre estabelecidos e outsiders, entendendo que o "[...] poder não é um amuleto que um indivíduo possua e outro não; é uma característica estrutural das relações humanas de todas as relações humanas" (Elias, 1970, p. 81).

É a partir das relações de poder entre sujeitos na escola que poderia resultar o reconhecimento de alguns direitos buscados por travestis e transexuais. Entre esses, podemos nomear os seguintes direitos: utilizar o nome social, externar comportamentos femininos, utilizar o banheiro de acordo com sua identidade de gênero, expressar trejeitos e maneirismos, enfim, poder se expressar sem se tornar alvo de humilhações, violências e perseguições. As garantias elaboradas no Plano Nacional de Promoção da Cidadania e Direitos Humanos LGBT (daqui por diante, PNLGBT), se efetivadas na educação, seriam um passo importante do reconhecimento de LGBT na escola e em outros locais, no mundo do trabalho, na sociedade civil, nas atividades esportivas e em tantos outros contextos. Vejamos algumas garantias como exemplo:

\begin{abstract}
Promover medidas que permitam o uso do nome social de travestis e transexuais no serviço público federal, tanto na administração direta quanto nas autarquias, fundações e empresas públicas. Produzir e/ou estimular a confecção e a divulgação de materiais didáticos e paradidáticos e de materiais específicos para a formação de profissionais da educação para a promoção do reconhecimento da diversidade de orientação sexual e identidade de gênero, inclusive em linguagens e tecnologias que contemplem as necessidades das pessoas com deficiências (Brasil, 2009, p. 31-32).
\end{abstract}

A afirmação desses documentos significa a criação de argumentos que passam a compor os discursos da militância LGBT, de gestores/ as públicos, pesquisadores/as etc., nas escolas e além destas. Todavia, os PY e as orientações de PNLGBT encontram, na escola, barreiras de diversas ordens. Esses obstáculos estão desde a sala de aula, passando pela gestão escolar e chegando até intervenções políticas nacionais como aquela referente à suspensão do material denominado Kit antihomofobia pela Presidência da República (Passarinho, 2011). Esse material poderia corroborar algumas propostas do PNLGBT.Entretanto, na contemporaneidade, a maior proximidade entre grupos outsiders e estabelecidos (Elias, 2006) pode modificar as figurações sociais, possibi-

Educação \& Realidade, Porto Alegre, v. 39, n. 1, p. 201-220, jan./mar. 2014. 207 
litando formas de reconhecimento percebidas nas falas das professoras entrevistadas. Isso indica que existem fissuras na heteronormatividade que permitiram às professoras entrevistadas, apesar da transfobia, conseguirem se formar e trabalhar no contexto educacional. A professora 2 diz não se lembrar de ter sofrido violências físicas na escola. Junto a isso, relatou acerca da gênese de seu desejo de ser professora e de como considera a agressividade um elemento que a fez adentrar os espaços que são negados a ela devido à sua travestilidade.

Não, eu nunca apanhei, eu nunca apanhei na vida, acho que é um grande recalque meu. Mesmo na rua com as meninas, eu nunca apanhei, então acho que isso foi me fazendo muito audaciosa, de querer romper espaço, de abrir porta e se a porta não se abre para mim eu chuto e faço ela abrir Então eu acho que isso me fez muito agressiva, muito determinada, também nunca bati, já tentei, mas nunca bati. Então, assim, isso foi me dando segurança, eu acho... De todas as agressões na escola isso foi me fazendo ver que não, que mesmo com todo esse contexto eu quero um emprego formal, eu quero ser professora, eu sempre me identifiquei com sala de aula com oito, nove anos meu pai me deu um quadro de criança, esses quadro de brincar, giz; então eu brincava de ser professora (Professora 2, 68, 2010).

A função de professora, entre outras que possibilitam a travestis e transexuais certa atribuição de valores, é bastante invisibilizada se considerarmos a ligação que se faz das travestis, como é o caso da professora 2, com o contexto da prostituição, dos shows em casas noturnas e como personagens caricatos em diversas mídias.

\section{Transexuais e Travestis e Transgêneros: in/definição de categorias}

No debate emergente sobre as sexualidades, é importante compreendermos algumas nuanças e alguns dissensos das categorias travestis, transexuais e transgêneros. Essas categorias podem dizer de diferentes contextos; por exemplo, os discursos médicos têm articulado a transexualidade mais ao transtorno de gênero a partir das normas de gênero (Bento, 2006), enquanto as travestis aparecem mais ligadas à prostituição, à violência e aos shows (Trevisan, 1996; Green, 2000; Benedetti, 2005; Pelúcio, 2009). Todavia, travestis e transexuais permanecem em grande parte consideradas pelo senso comum como homens que se vestem de mulher. Essas são constituídas nos índices precários de uma semântica da estigmatização dos outsiders. As travestis são consideradas muitas vezes outsiders no próprio movimento LGBT, pois a relação delas com prostituição, drogas e violência é muitas vezes generalizada, servindo como um estigma atribuído a sujeitos do grupo outsider. Essa é uma questão complexa, pois mesmo entre muitas travestis e transexuais existe uma compreensão de que a prostituição poderia ser considerada um rito de passagem ou ainda mesmo como uma necessidade de sobrevivência e/ou uma possibilidade desses sujeitos (Benedetti, 2005; Pelúcio, 2009). Observamos que várias entrevistadas de nossa pesquisa 
e outras encontradas em nossas observações de campo não têm consenso sobre o significado da prostituição, inclusive muitas afirmam nunca terem passado por essa experiência. Nos encontros de travestis e transexuais em que participamos e nas entrevistas realizadas com as sete professoras, as falas são marcadas por discursos da academia, do movimento LGBT e das políticas públicas, entre outros. As tentativas de diferenciação das categorias se des/articulam nas pesquisas acadêmicas, nas lutas da militância, nas políticas públicas, na história de vida de cada professora entrevistada e revelam aproximações de identidades coletivas e/ou políticas. Vejamos outras questões mais específicas das diferenciações das categorias e suas in/definições.

A categoria transexual, bastante popularizada nos últimos anos, tem um histórico próprio. Conforme Bento (2006), a transexualidade deriva dos discursos ligados às ciências médicas e psicológicas do início do século XX, quando, em 1910, Magnus Hirschfeld utilizou o termo transexualpsíquico. Segundo a pesquisadora, a separação entre transexuais, travestis e homossexuais se dá mais intensamente na segunda metade do século XX: de diferentes modos, as transexuais são consideradas fruto de questões endocrinológicas e/ou da educação, perspectivas que culminam nas justificativas de tratamento e medicalização dos sujeitos, ou seja, da patologização de transexuais e travestis. Em nossa pesquisa, entendemos como transexuais femininas e/ou mulheres transexuais as que foram definidas como homens no nascimento, porém se percebem como mulheres ao longo da vida. Esse modo de nomeação está em consonância com pesquisas (Bento, 2006), os PY e o PNLGBT que, em certa medida, se afastam de posições das ciências médicas, entre outras, que classificam sujeitos definidos no nascimento como homens, considerando-os transexuais masculinos. Essa definição afronta os sujeitos que não se reconhecem em corpos a partir do sistema sexo-gênero orientado pelas normas de gênero.

Dentro da perspectiva queer, autores utilizam o termo transgênero para indicar alguém que se sente pertencente ao "[...] gênero oposto, ou pertence a ambos ou nenhum dos dois sexos tradicionais, incluindo travestis, transexuais, intersexuais, Drag Queens e Drag Kings" (Ávila; Grossi, 2010, p. 2). Entre nossas entrevistadas, uma professora definiuse como transexual e queer. Ela possui muita proximidade com acadêmicos considerados pós-identitários. Ao utilizar o termo queer, a professora procurou se afastar de posições que poderíamos denominar identitárias, aproximando-se da definição de transgênero, conforme Ávila e Grossi elaboram em seu texto. Contudo o termo transgênero e queer, quando utilizado como autoatribuição de sujeitos, parece não ser de uso corrente no Brasil. Ao mesmo tempo, consideramos que tais termos, articulados em contextos específicos da academia, podem se tornar comuns se continuamente apropriados pelos sujeitos.

Para Miguel Almeida (2010), a lógica queer não seria viável para determinadas regiões do mundo, entre elas a América Latina e segmen- 
Professoras Transexuais e Travestis no Contexto Escolar

tos populares do Ocidente em geral, lugar das professoras que pesquisamos. Para esse autor, a desconstrução das identidades sociais, que ele compreende ser defendida por autores da Teoria Queer, implica a desconsideração da importância das lutas de muitos coletivos de LGBT. As posições identitárias estariam organizadas via uma agenda de combate à homofobia e direitos humanos e cidadania LGBT. No Brasil, essa agenda cresceu e se consolidou nos movimentos sociais LGBT com as políticas públicas de prevenção e tratamento do HIV/Aids no final do século XX (Carvalho, 2011). Consideramos que tanto a Teoria Queer como argumentos de outras teorias sociais não podem ser reduzidos a algumas posições autorais que utilizamos, pois as formas de vida apresentadas pelos sujeitos, seja como efeito da discursividade, seja como constituído em dinâmicas inter-relacionais, desafiam qualquer pretensão de autossuficiência conceitual no campo que poderíamos indicar como aquele que analisa o sistema sexo-gênero. Almeida (2010) propõe uma distinção entre reflexão crítica e ação política, retomando a questão do essencialismo estratégico. Richard Miskolci questiona essa posição, considerando-a um itinerário liberal-identitário que é redutor daquilo que propõe a crítica queer, e justifica seu argumento:

Diante desta nostalgia do essencialismo estratégico, vale recordar que Foucault, antes de Spivak, posicionou-se sobre o uso tático da identidade, ou seja, apenas em contextos pontuais e de curto prazo, mas, no longo prazo, defendeu a necessidade de uma estratégia não identitária (Miskolci, 2011, p. 66).

Consideramos que essa discussão interfere no modo como travestis e transexuais se compreendem, "[...] conceitos criados no meio acadêmico neste campo de estudos são logo absorvidos pelos sujeitos e pelos movimentos sociais" (Barbosa, 2010, p. 117). Percebemos que as professoras transexuais femininas e/ou travestis que entrevistamos apoderam-se desses conceitos a partir da capacidade de essas categorias fornecerem, ou não, alguma legitimação na figuração estabelecidos-outsiders. Consideramos, a partir das entrevistas, que essa recusa do termo é feita em grande medida pelo movimento LGBT, contudo entendemos como importante a questão posta pela perspectiva queer nos debates acadêmicos. No entanto travestis e transexuais, professoras ou não, em vários momentos das entrevistas e das observações de campo, se diziam queer, pois se afirmavam como mulheres de pênis. Não desejavam a neovagina, mas se consideravam transexuais. Esse modo de se compreender como mulher de pênis colocaria em xeque a construção da heterossexualidade, pois se afasta de qualquer identidade naturalizada. Para as professoras de nossa pesquisa, essa definição é muito mais ligada às discussões acadêmicas e do movimento LGBT que a seu cotidiano na escola. A complexidade dos significados das categorias travesti e transexual foi analisada por Barbosa (2010, p. 117), que buscou demonstrar que elas são apreendidas e elaboradas "[...] além das convenções médicas. Conceitos criados no meio acadêmico neste

210 Educação \& Realidade, Porto Alegre, v. 39, n. 1, p. 201-220, jan./mar. 2014 Disponível em: <http://www.ufrgs.br/edu_realidade> 
campo de estudos são logo absorvidos pelos sujeitos e pelos movimentos sociais”. As articulações que os sujeitos ainda podem fazer dessas categorias são apontadas por Larissa Pelúcio:

\begin{abstract}
[...] com pessoas que se autoidentificavam como transexuais, mas viviam, segundo elas mesmas, como travestis, pois se prostituíam e faziam uso sexual do pênis. Assim como estive com travestis que, em algum momento da sua vida, desejariam retirar o pênis; e outras que jamais haviam pensado naquilo, mas que começavam a estudar essa possibilidade mais recentemente, passando a cogitar a possibilidade de serem transexuais (Pelúcio, 2007 apud Barbosa, 2010, p. 110).
\end{abstract}

A identificação do sujeito acerca de si, ainda que vacilante, transitória, rígida, fora dos padrões de inteligibilidade para muitos, simulada, entre tantas outras, é legítima. Ela diz das histórias das des/identificações do sujeito, da construção e das negociações das professoras em questão com identidades coletivas e políticas, sejam elas ligadas a uma identidade política LGBT e/ou transexual, travesti ou transgênero. Assim, compreendemos a importância de uma análise não essencialista dos sujeitos por nós denominados como outsiders. Contudo consideramos que as identidades coletivas e políticas de travestis e transexuais podem ser compreendidas numa relação processual e dinâmica, em figurações de vários níveis. A emergência dos coletivos específicos de travestis e transexuais no final do século XX e da Rede Trans Educ no início do século XXI são exemplos disso. O que consideramos problemático é analisar dicotomicamente nossos sujeitos em relação aos contextos sociopolíticos em que eles emergem, ou ainda utilizar teorias e conceitos como camisas de força em análises que teimam em enquadrar os objetos em determinados arcabouços teóricos.

Nossas entrevistadas apontam uma constante negociação no contexto escolar, percebemos que a noção de identidade de gênero, a defesa do uso do nome social, a defesa acerca da legitimidade de direitos para LGBT, encontrados nos dois documentos analisados, eram argumentos que faziam parte daqueles utilizados pelas professoras travestis e/ou transexuais nas dinâmicas relacionais da escola. Esses documentos emergem na década de 2010 como resultado das lutas de coletivos de LGBT nas políticas de direitos humanos (Correa, 2009). O documento PY emerge no cenário internacional em 2006, a partir de um histórico das lutas para pautar orientação sexual e identidade de gênero no contexto dos direitos humanos (Correa, 2009). O PNLGBT surge no Brasil em 2009 como resultado da articulação de coletivos do movimento social e agentes públicos. No Brasil, esses documentos são divulgados de modo estratégico por coletivos como a Associação Brasileira de Lésbicas, Gays, Bissexuais, Travestis e Transexuais (ABGLT), criada em 1995, e a Articulação Nacional das Travestis, Transexuais e Transgêneros (ANTRA), criada em 2000. No caso específico das professoras travestis e/ou transexuais, esses argumentos das políticas de direitos 
humanos e noções como identidade de gênero funcionam como pontes semânticas nas disputas em que a transfobia se coloca como obstáculo ao reconhecimento. Porém consideramos que essa não é uma estratégia isolada para o reconhecimento utilizada pelas professoras travestis e/ ou transexuais.

Com as professoras entrevistadas, observamos que se assumir publicamente como transexual ou travesti, realizar as mudanças corporais e no vestuário de acordo com sua identidade de gênero é colocar-se num lugar ameaçado. Ao mesmo tempo, é demandar reconhecimento pela sua forma de vida, exigir direitos como os demais sujeitos, desidentificar-se do grupo de outsiders. Esse lugar pode ser como profissionais do sexo ou na função de docente. Essa questão aparece na descrição do medo presente em assumir-se como transexual e/ou travesti, passar de professor a professora:

A gente tem medo de qualquer coisa quando tu estás num processo assim. Tu estás se expondo e tal, então é o mesmo medo da rua. Quando tu estás numa rua, trabalhando ou se virando, enfim tu tens ao mesmo tempo em que tu tens aquela coisa assim da arrogância e da petulância, mas tu tens o medo por trás. Tem toda a questão do medo, então eu acho que isso é uma coisa assim que eu tive, com certeza... Mas eu tava ao mesmo tempo tranquila, porque eu sabia que demitida eu não seria, nem poderia, daí seria um outro processo na vida deles. Outra era essa questão assim de talvez o máximo que acontecesse era eu ter que sair da escola, trocar de escola, já chegar com a identidade de feminina em outra escola (Professora 1, 2010).

O sentimento de medo na rua aparece relacionado ao medo de ser demitida, e revela que a vulnerabilidade sentida na rua e nos programas se liga ao mundo do trabalho; ambos são lugares marcados pela transfobia. Este termo pode indicar um dos dispositivos dinâmicos da heteronormatividade que atinge especificamente o modo de vida daqueles/ as que se autodefinem como transexuais ou travestis. Na escola, a ridicularização e/ou o impedimento do nome social das professoras entrevistadas é um exemplo dessa especificidade. No entanto as professoras, quando descoladas da posição de outsider, conseguiam reagir a isso. A professora 1, ao dizer "daí seria um outro processo na vida deles", caso não respeitassem aquilo que ela define como identidade de gênero, demonstra que há um sentimento de injustiça, e ela pensa nos recursos e nas estratégias que poderia mobilizar. Em relação à possível demissão, a professora nomeia estratégias: processar aqueles que poderiam vir a dispensá-la e procurar outra escola, aonde ela chegaria como mulher trans. Nessa fala, ela se percebe em relação a outros sujeitos que a ameaçam e precisam ser enfrentados. Todavia, quando as demissões ocorreram, no caso das professoras 1 e 3 , foram justificadas formalmente por outras questões. Posteriormente, essas duas professoras confirmaram, por diálogos com antigos colegas de trabalho, que foram demitidas por pessoas que elas definiram como homofóbicas. A professora 1 foi demitida ainda como homossexual, segundo seu relato, na época da entrevista ela estava empregada: "Eu fiz magistério depois me formei com 18

212 Educação \& Realidade, Porto Alegre, v. 39, n. 1, p. 201-220, jan./mar. 2014 Disponível em: <http://www.ufrgs.br/edu_realidade> 
anos, fui começar a trabalhar na escola particular, fui demitido por ser homossexual, não assumido, mas eu fiquei sabendo após três anos que eu não era incompetente, mas eu era gay" (Professora 1, 2010).

No relato da professora 3, temos uma informação além das demissões e suas falsas justificativas: ela isenta aqueles que a demitem, pois ela foi demitida após a transformação, contudo as demissões sempre ocorriam de maneira sutil:

Eu ganhei a conta na rádio, eu trabalhava numa rádio educativa, trabalhei 11 anos, então ganhei a conta, já sabia que ia ganhar, já sabia, "ah, foi porque é corte de pessoal”, mas sabia que não era, e aí eu ganhei a conta seguidamente também, em casa, nas férias. Entrei em férias e aí quando foi em janeiro, no início de janeiro foi uma pedagoga na minha casa e ela disse assim "olha, virá uma professora de (nome da cidade) que é formada em história", que eu sabia que era mentira, "que vai tomar o seu lugar, então é pra você assinar aqui uma rescisão contratual”, e eu assinei. Eu sabia, porque tu imaginas, eu não vou expor o colégio que não tem nada a ver, que quando eu fui contratada eu fui contratada como professor e fui contratada esperando uma postura de professor e agora uma coisa íntima vou expor o colégio, vou expor meus alunos, entendeu? Eu não tenho esse direito, é o que eu pensei, então por isso que eu não fiz exatamente nada contra o colégio, porque o colégio que nunca me tratou mal... (Professora 3, 2010).

Na figuração estabelecidos-outsiders, a professora 3 sente-se errada, percebendo-se culpada pela explicitação da transexualidade, demitida da rádio e do colégio, tendo assim reiterado seu lugar de outsider como justificativa para sua demissão: "quando eu fui contratada eu fui contratada como professor e fui contratada esperando uma postura de professor". A noção de individualidade do sujeito se refere às lógicas da estrutura de sua autorregulação em relação aos objetos, inclusos, nestes, outros sujeitos; com isso, percebemos a complexidade da autopercepção daqueles constituídos como outsiders. Tais lógicas não são herdadas como o são as características biológicas da reprodução, da respiração etc. Esse processo de individualização pelas lógicas de autorregulação, explicitamente marcado pela heteronormatividade, está diretamente relacionado ao conjunto de relações do indivíduo. Nas entrevistas, percebemos que os documentos eram um suporte para quaisquer mobilizações, pois todas as entrevistadas utilizavam as noções de identidade de gênero ou mesmo citavam diretamente os documentos como o PY e o PNLGBT; além destes, existiam outras formas de apoio que elas recebiam de colegas de trabalho, alunos/as e gestores/as, ainda que parcimoniosamente. Assim, podemos compreender que, no contexto das professoras travestis e/ou transexuais, existem discursos e práticas sociais que podem fornecer redefinição das relações que as constituem como outsiders. Portanto entendemos que essas transexuais e travestis que chegam como professoras na sala de aula dizem das tessituras das teias de interdependências sociais e não de uma qualidade de sujeitos isolados. Elas embaçam os limites entre masculino e feminino, ou seja, a naturalização da heterossexualidade; a presença delas na 
escola pode colocar em xeque a heteronormatividade, assim elas permanecem sempre atentas à possibilidade de serem eliminadas. Isto é algo bastante tenso nos relatos das entrevistas.

\section{Professoras Transexuais Femininas e/ou Travestis: a partir e além da patologia e da prostituição}

A emergência das professoras transexuais e/ou travestis pode indicar a direção das mudanças nas relações de poder entre estabelecidos-outsiders no processo social, portanto referindo-se "[...] às transformações amplas, contínuas, de longa duração - ou seja, em geral não aquém de três gerações" (Elias, 2006, p. 28). No século XX, as questões postas pelo movimento feminista e pelos movimentos homossexuais "consideraram a importância de fornecer espaços identitários para se assumir sua condição homossexual" (Silva, 2009, p. 154). Isso se deu principalmente com o nascente movimento gay estadunidense na década de 1960, desde o enfrentamento dos policiais por gays e lésbicas na boate Stonewall no ano de 1969, em Nova York. Como aponta Alessandro Silva (2009), tais lutas tornaram públicas demandas de homossexuais que estavam em espaços íntimos e privados; deslocavam o debate da sexualidade humana também para o espaço político. Nesse contexto se consolidam várias questões demandadas politicamente desde aquele período. Stonewall é um acontecimento marcante no movimento LGBT contemporâneo por vários motivos:

Eles [os motivos] se diferenciam em função de sua inserção na realidade social e das transformações em curso nos contextos sociais, histórico, cultural, político e econômico, em que emergem, na busca de princípios de equivalência de direitos, não apenas sociais, mas humanos, como também na busca do reconhecimento identitário (Silva, 2009, p. 154).

Essas demandas indicavam algumas direções do processo social, como a politização e as definições identitárias nos movimentos homossexuais e as lutas pelo aumento da visibilidade LGBT nos contextos sociais. Pode-se considerar que observamos no processo social um menor distanciamento entre estabelecidos e outsiders, conforme apontado por Elias (2006) como uma das características do século XX. Enquanto nos Estados Unidos isso se deu mais na sociedade civil não estatal, no Brasil os movimentos homossexuais e atualmente o movimento LGBT articularam-se ao redor das políticas públicas do HIV/Aids. As buscas de definição de uma identidade transexual, feminina, travesti, ainda que precária e transitória, estão relacionadas com essa história, sendo que a diferenciação de transexuais e travestis dos homossexuais se deu apenas em finais do século XX (Bento, 2006). É esse o contexto no qual se forma a figuração estabelecidos-outsiders em diferentes níveis, em que a disputa pelo reconhecimento das transexuais, travestis, transgêneros, entre outras, tem sido travada. 
Assim, o reconhecimento que podemos considerar em relação às transexualidades e às travestilidades está pautado no cotidiano pela heteronormatividade, não se dá no vazio. Como as regras, observadas ou não, de um jogo de cartas, documentos como os PY, o PNLGBT e pareceres locais sobre nome social podem indicar tanto uma subversão da heteronormatividade como a sua consolidação. Ao mesmo tempo em que fornecem possibilidades de reconhecimento identitário, podem submetê-las às normas de gênero apontadas por Judith Butler (1999). Isso nós percebemos ao identificar nas entrevistas da pesquisa, em que as professoras travestis e/ou transexuais ainda permanecem em zonas de tolerância negociada.

Na comunidade escolar, as relações entre membros do contexto escolar e as professoras travestis e/ou transexuais podem mudar as dinâmicas de poder entre estabelecidos e outsiders. Essa mudança tem sido conseguida dentro de processos sociais que têm desenvolvido novas compreensões da sexualidade humana, algo que parece presente em documentos como o PNLGBT, mas também em eventos como Stonewall. Contudo, apesar dessas aparentes conquistas, no ambiente escolar as travestis e/ou transexuais que entrevistamos, ainda que na função de professora, são definidas como alguém perigoso, a ser barrado. Suas presenças são firmadas muitas vezes por processos judiciais, porém isso não garante sua integração à comunidade escolar, pois as emoções marcam a relação de poder nas figurações sociais. A figuração sempre é marcada por indícios da barreira emocional entre estabelecidos e outsiders:

Mais do que qualquer outra coisa, talvez essa barreira afetiva responda pela rigidez, amiúde extrema, da atitude dos grupos estabelecidos para com os grupos outsiders pela perpetuação do tabu contra o contato mais estreito com os outsiders, geração após geração, mesmo que diminua sua superioridade social ou, em outras palavras, seu excedente de poder (Elias; Scotson, 2000, p. 25).

No contexto brasileiro os sujeitos estão regidos por uma suposta moral laica em relação aos LGBT. Entretanto, devido a seus elementos religiosos, suscitam emoções históricas e socialmente herdadas da moral judaico-cristã. Na escola, sentidos articulados por sujeitos no histórico religioso do Ocidente são atribuídos à vivência e à expressão da sexualidade. Numa pesquisa de opinião pública realizada pelas fundações Perseu Abramo e Rosa Luxemburgo (Venturi; Bokany, 2011), foi citada a seguinte frase: "Deus fez o homem e a mulher [com sexos diferentes] para que cumpram seu papel e tenham filhos". Na população entrevistada, essa frase teve uma concordância de 11 em cada 12 brasileiros/as. Segundo os dados da pesquisa, 92\% dos entrevistados concordam, em algum grau, com a frase citada e $84 \%$ deles concordam totalmente com essa frase; apenas $8 \%$ teriam uma concordância parcial com a afirmação feita. Desse modo, as figurações sociais em que locali- 
zamos as professoras entrevistadas são marcadas pela forte presença de elementos religiosos que corroboram a heteronormatividade.

Essas professoras têm conseguido firmar-se por diversos modos, entre os quais consideramos as medidas judiciais e as alianças com movimentos sociais e organizações LGBT, mas sobretudo pelo reconhecimento e autorreconhecimento de poder exercer a função de professora. Isso aparece nas entrevistas com a professora 1, que tem articulado uma rede de professoras transexuais femininas e travestis. Ela relata que através de seus contatos e participações no movimento LGBT encontrou outras professoras e teve a ideia da rede. Na descrição dos objetivos da rede, percebemos que existe a elaboração de uma identidade coletiva de travestis e transexuais na educação e no movimento LGBT:

O objetivo principal dessa rede é desmistificar [sic] essa questão de que uma trans não pode estar em determinado lugar. Por que ela só tem que estar no salão de beleza ou sendo enfermeira ou sendo profissional do sexo? Por que não poderíamos ter trans...? A gente sabe que tem trans advogadas, trans médicas, já tem uma ou duas médicas. [...] Por que não na educação, que também faz parte desse contexto? Então o objetivo principal é divulgar, quer dizer, mostrar a cara e realmente saber que estamos ligadas, que o principal é justamente esse, estar à frente desse contexto... Por que tem tantas meninas que estão fora da escola? Por que que muitas abandonam, a gente sabe que hoje o maior índice dentro do Movimento LGBT de evasão e preconceito é em relação às trans e travestis? Por quê? Por que elas abandonam antes? Por que tem a questão do nome social, todas essas questões? Então um dos motivos que a gente de repente, não que vai ser exemplo, mas que vai ser um apoio pra que elas querem ter coragem de voltar pra escola, também essa é uma coisa que eu acho que é importante da gente. Nesse sentido, assim, o objetivo principal é realmente se articular enquanto uma rede de profissionais, mas que tenha esse diferencial, assim, de realmente lutar pelos direitos que a gente sabe que tem (Professora 1, 2010).

Consideramos, portanto, que identidades políticas LGBT, ainda que transitórias e/ou estratégicas, têm sido importantes para as trans. A identidade coletiva de professoras travestis e/ou transexuais emerge da narrativa da professora 1, mas está intimamente ligada a uma identidade política dos movimentos LGBT no Brasil. Ao mesmo tempo, entendemos que as políticas da educação sobre diversidade sexual, como a formação de professores/as, publicação de materiais e livros sobre educação e homofobia, não barram aqueles/as que compreendem a presença de professoras transexuais femininas ou travestis como uma ameaça, como uma possibilidade de contaminação dos corpos heterossexuais. É o fantasma que acompanha os outsiders, sua possibilidade de manchar a reputação moral, contaminar os corpos, questionar os privilégios dos estabelecidos.

\section{Considerações Finais}

A entrada e a manutenção das professoras travestis femininas e/ ou transexuais no ambiente escolar podem mostrar além da submissão 
aos estabelecidos: indicam também algumas direções da mudança nas relações de poder entre estabelecidos e outsiders. Nesse sentido, para compreender essa discriminação, aqui mencionada, é preciso entender o funcionamento dos dispositivos das normas de gênero, como a transfobia, na regulação das dinâmicas inter-relacionais. Esses dispositivos exercem um papel crucial nas interdependências sociais para definir, utilizando as hierarquias sexuais, um grupo de outsiders. LGBT e outras formas de vida em conflito com a heteronormatividade são rechaçadas como algo a ser eliminado, combatido e/ou subalternizado pelos discursos articulados na história do Ocidente. Nessa perspectiva, compreendemos algumas professoras travestis e/ou transexuais na busca constante de reconhecimento, ainda que construindo um corpo normalizado de mulher, regido em certa medida pelas normas de gênero. A contingência dessas normas pode ser observada na medida em que determinadas formas de vida transitam pelas sexualidades e pelo gênero. As professoras entrevistadas em nossa pesquisa, ao aproximaremse do corpo da mulher heterossexual, tornam-se mais aceitáveis; esta é uma aproximação que sempre aparece como insuficiente e ao mesmo tempo desnaturaliza a definição de homem e mulher. Contudo as professoras que entrevistamos mostram que, ao estabelecerem relações de solidariedade e apoio com outros sujeitos, como alunos/as, indicam um distanciamento do lugar de outsider.

À professora travesti e/ou transexual parece estar reservado o lugar de uma professora outsider, por isso sua luta é no sentido de se adequar ao corpo da mulher heterossexual já dado pela heteronormatividade. O corpo postulado como uma materialidade anterior ao discurso será sempre algo prévio, uma essência que precede a ação. Isso implica reconhecer que a compreensão de um corpo de mulher poderá ser sempre problemática por delimitar e circunscrever esses sujeitos através de discursos que se tornam obstáculos ao reconhecimento de outras performatividades desse corpo. Na escola e na sociedade em geral se reiteram as normas de gênero pelos discursos religiosos, médicos e morais. Portanto o lugar de professora torna-se, para muitos, uma dignidade imprópria às transexuais e travestis. Todavia também é possível observar outras dinâmicas no contexto dessas professoras outsiders, elas contam a seu favor outras possibilidades de reconhecimento nas alianças com o movimento LGBT, nas noções emergentes tanto nos PY como no PNLGBT. Todavia as garantias legais não significam a efetivação dos direitos nem a suspensão da violência. A favor dos estabelecidos temos as constelações de emoções que mesclam tradições morais, argumentos religiosos, discursos médicos a reiterar o lugar de outsiders às aquelas autoidentificadas como travestis e/ou transexuais femininas. Nesse sentido, entendemos que essa busca das professoras entrevistadas pelo feminino idealizado pauta-se por processos extremamente complexos e tensos nas relações com a escola e fora dela.

Consideramos ser possível dizer que a direção das mudanças nos processos sociais envolve LGBT em geral, e travestis e transexuais de

Educação \& Realidade, Porto Alegre, v. 39, n. 1, p. 201-220, jan./mar. 2014

Disponível em: <http://www.ufrgs.br/edu_realidade> 
forma específica. A direção das mudanças indica um acirramento das posições na figuração estabelecidos-outsiders. A possibilidade de permanência na função de professora ainda não garante a possibilidade de deslocamento de sua posição de outsider. Assim, podemos dizer que para essas professoras nada está garantido, pois nas relações de poder pautadas pela des/ordem das emoções, na revanche dos estabelecidos saudosos dos privilégios da heterossexualidade, a homofobia/transfobia parece espreitar as noções do reconhecimento da cidadania e dos direitos humanos de professoras transexuais e/ou travestis.

Recebido em 11 de junho de 2012 Aprovado em 04 de outubro de 2012

\section{Notas}

$1 \mathrm{O}$ uso da sigla LGBT (lésbicas, gays, bissexuais, travestis e transexuais) foi definido na $1^{a}$ Conferencia Nacional de GLBT em Brasília no ano de 2008 e tem sido utilizado com mais frequência do que outras siglas no contexto brasileiro. O deslocamento da palavra lésbica para o início da sigla pretendeu indicar uma valorização das questões de gênero no movimento LGBT brasileiro que historicamente priorizou as questões relativas aos gays. Observamos o uso dessa sigla considerando a legitimidade das demandas de coletivos presentes naquela conferência e estamos cientes que são elaborações que conhecem variações por diferentes motivos no histórico do movimento social.

2 Os locais das entrevistas com as professoras 1, 2 e 3 não serão informados, para evitar sua identificação, pois elas preferiram ficar anônimas.

\section{Referências}

ALMEIDA, Miguel Vale. A Chave do Armário: homossexualidade, casamento e família. Florianópolis: Ed. da UFSC, 2010.

ÁVILA, Simone; GROSSI, Miriam Pillar. Transexualidade e Movimento Transgênero na Perspectiva da Diáspora Queer. In: CONGRESSO DA ASSOCIAÇÃO BRASILEIRA DE ESTUDOS DA HOMOCULTURA, 5., 2010, Natal. Anais eletrônicos... Natal: ABEH, 2010. Disponível em: <http://pt.scribd.com/doc/59733080/TRANSEXUALIDADE-E-MOVIMENTO-TRANSGENERO-NA-PERSPECTIVA-DA-DIASPORA-QUEER-Simone-Avila-e-Miriam-Pillar-Grossi>. Acesso em: 7 mar. 2011.

BARBOSA, Bruno Cesar. Normas e Diferenças: uma etnografia dos usos das categorias travesti e transexual. 2010. 130 f. Dissertação (Mestrado em Antropologia) - Programa de Pós-Graduação em Antropologia Social. Universidade de São Paulo, São Paulo, 2010.

BENEDETTI, Marcos. Toda Feita: o corpo e o gênero das travestis. Rio de Janeiro: Garamond, 2005.

BENTO, Berenice. A Reinvenção do Corpo: sexualidade e gênero na experiência transexual. Rio de Janeiro: Garamond, 2006.

BORRILLO, Daniel. Homofobia: história e crítica de um preconceito. Belo Horizonte: Autêntica, 2010.

BRASIL. Secretaria Especial de Direitos Humanos. Plano Nacional de Promoção da Cidadania e dos Direitos Humanos LGBT. Brasília: Secretaria Especial de Direitos Humanos, 2009.

BUTLER, Judith. Gender Trouble: feminism and the subversion of identity. New York/London: Routledge, 1999.

218 Educação \& Realidade, Porto Alegre, v. 39, n. 1, p. 201-220, jan./mar. 2014 Disponível em: <http://www.ufrgs.br/edu_realidade> 
BUTLER, Judith. Deshacer el Género. Barcelona: Paidós, 2006.

CARRARA, Sérgio; VIANNA, Adriana Resende. “Tá Lá o Corpo Estendido no Chão...": a violência letal contra travestis no município do Rio de Janeiro. Physis, v. 16, n. 2, p. 233-249, 2006.

CARVALHO, Mário Felipe de Lima. Que Mulher É Essa? Identidade, política e saúde no movimento de travestis e transexuais. 2011. 147f. Dissertação (Mestrado em Saúde Coletiva) - Programa de Pós-Graduação em Saúde Coletiva, Universidade do Estado do Rio de Janeiro, Rio de Janeiro, 2011.

CORREA, Sônia. O Percurso Global dos Direitos Sexuais: entre "margens" e "centros". Bagoas: Estudos Gays, Gêneros e Sexualidades, n. 4, p. 17-42, jan./jun. 2009. Disponível em: <http://www.cchla.ufrn.br/bagoas/v03n04bagoas04.pdf>. Acesso em: 15 jul. 2010.

CORRÊA, Sônia; MUNTARBHORN, Vitit (Org.). Princípios de Yogyakarta: princípios sobre a aplicação da legislação internacional de direitos humanos em relação à orientação sexual e identidade de gênero. 2006. Disponível em: <http:// www.clam.org.br/pdf/principios_de_yogyakarta.pdf >. Acesso em: 12 nov. 2007. DÍAZ, Margarita; CHINAGLIA, Magda; DÍAZ, Juan. Estudo Qualitativo Sobre a Homofobia no Ambiente Escolar em 11 Capitais Brasileiras. Campinas: Reprolatina, 2011. 70 p. Disponível em: <http://www.reprolatina.org.br/site/html/ atividades/downloads/escola_sem_homofobia/Relatorio_Tecnico_Final.pdf $>$. Acesso em: 12 jun. 2012.

ELIAS, Norbert. Introdução à Sociologia. Lisboa: Edições 70, 1970.

ELIAS, Norbert. Escritos e Ensaios 1: Estado, processo, opinião pública. Rio de Janeiro: Jorge Zahar, 2006.

ELIAS, Norbert; SCOTSON, John. Os Estabelecidos e os Outsiders: sociologia das relações de poder a partir de uma pequena comunidade. Rio de Janeiro: Jorge Zahar, 2000.

FRANCO, Neil. A Diversidade Entra na Escola: histórias de professores e professoras que transitam pelas fronteiras da sexualidade e do gênero. 2009. 239f. Dissertação (Mestrado em Educação) - Programa de Pós-Graduação em Educação, Universidade Federal de Uberlândia, Uberlândia, 2009.

FUNDAÇÃO INSTITUTO DE PESQUISAS ECONÔMICAS (FIPE); INSTITUTO NACIONAL DE ESTUDOS E PESQUISAS EDUCACIONAIS ANÍSIO TEIXEIRA (INEP); MINISTÉRIO DA EDUCAÇÃO (MEC). Projeto de Estudo Sobre Ações Discriminatórias no Âmbito Escolar, Organizadas de Acordo com Áreas Temáticas, A Saber, Étnico Racial, Gênero, Orientação Sexual, Geracional, Territorial, Pessoas com Necessidades Especiais (Deficiência) e Socioeconômica. São Paulo: FIPE/MEC/ INEP, 2009. Disponível em: <http://portal.mec.gov.br/dmdocuments/relatoriofinal.pdf $>$. Acesso em: 6 out. 2009.

GREEN, James. Além do Carnaval: a homossexualidade masculina no Brasil do século XX. São Paulo: UNESP, 2000.

HONNETH, Axel. Luta por Reconhecimento: a gramática moral dos conflitos sociais. São Paulo: Ed. 34, 2003.

JUNQUEIRA, Rogério Diniz (Org.). Diversidade Sexual na Educação: problematizações sobre homofobia nas escolas, v. 32. Brasília: Ministério da Educação; Unesco, 2009.

LIONÇO, Tatiana; DINIZ, Débora (Org.). Homofobia e Educação: um desafio ao silêncio. Brasília: Editora UNB, 2009.

LOURO, Guacira Lopes. Gênero, Sexualidade e Educação: uma abordagem pósestruturalista. Petrópolis: Vozes, 1997. 
LOURO, Guacira Lopes. Heteronormatividade. In: JUNQUEIRA, Rogério Diniz (Org.). Diversidade Sexual na Educação: problematizações sobre homofobia nas escolas, v. 32. Brasília: Ministério da Educação; Unesco, 2009. P. 85-93.

MISKOLCI, Richard. A Teoria Queer e a Sociologia: o desafio de uma analítica da normalização. Sociologias, Porto Alegre, v. 11, n. 21, p. 159-182, jan./jun. 2009.

MISKOLCI, Richard. Não ao Sexo Rei: da estética da existência foucaultiana à política queer. In: SOUZA, Luiz Antônio Francisco de; SABATINE, Thiago Teixeira; MAGALHÃES, Boris Ribeiro de (Org.). Michel Foucault: sexualidade, corpo e direito. Marília: Cultura Acadêmica, 2011. P. 47-68.

MOTT, Luis; ALMEIDA, Cláudio; CERQUEIRA, Marcelo. Epidemia do Ódio: 260 homossexuais foram assassinados no Brasil em 2010. 2011. Disponível em: <http://www.ggb.org.br/Assassinatos\%20de\%20homossexuais\%20no\%20Brasil\%20relatorio\%20geral\%20completo.html>. Acesso em: 10 dez. 2011.

PASSARINHO, Nathalia. Dilma Rousseff Manda Suspender Kit Anti-Homofobia, Diz Ministro. G1 - Portal de Notícias da Globo. 25 maio 2011. Disponível em: <http://gl.globo.com/educacao/noticia/2011/05/dilma-rousseff-manda-suspender-kit-anti-homofobia-diz-ministro.html>. Acesso em: 30 maio 2011.

PELÚCIO, Larissa. Abjeção e Desejo: uma etnografia travesti sobre o modelo preventivo de AIDS. São Paulo: Fapesp, 2009.

PRADO, Marco Aurélio Máximo; JUNQUEIRA, Rogério Diniz. Homofobia, Hierarquização e Humilhação Social. In: VENTURI, Gustavo; BOKANY, Vilma (Org.). Diversidade Sexual e Homofobia no Brasil. São Paulo: Editora Fundação Perseu Abramo, 2011. P. 51-72.

RAMIRES, Luiz. Homofobia na Escola: o olhar de um educador social do movimento LGBT. In: VENTURI, Gustavo; BOKANY, Vilma (Org.). Diversidade Sexual e Homofobia no Brasil. São Paulo: Editora Fundação Perseu Abramo, 2011. P. 131140.

SILVA, Alessandro Soares. Luta, Resistência e Cidadania: uma análise psicopolítica dos movimentos e paradas do orgulho LGBT. Curitiba: Juruá, 2009.

TREVISAN, João Silvério. Devassos no Paraíso: a homossexualidade no Brasil, da colônia à atualidade. Rio de Janeiro: São Paulo: Record, 1996.

VENTURI, Gustavo; BOKANY, Vilma (Org.). Diversidade Sexual e Homofobia no Brasil. São Paulo: Editora Fundação Perseu Abramo, 2011.

Marco Antônio Torres é doutor em Psicologia Social pela Universidade Federal de Minas Gerais (UFMG) com estudos na área da educação, diversidade sexual e participação social. É professor da Universidade Federal de Ouro Preto (UFOP), vinculado ao Departamento de Educação e ao Programa de Pós-Graduação em Educação, com atuação junto aos Núcleos de Pesquisa em Direitos Humanos e Cidadania LGBT (NUH/UFMG) e Caleidoscópio (UFOP).

E-mail: torresgerais@gmail.com

Marco Aurélio Prado é doutor em Psicologia Social pela Pontifícia Universidade Católica de São Paulo com estudos sobre participação social, identidades coletivas e movimentos sociais. É professor junto ao Programa de Pós-Graduação em Psicologia e pesquisador nos Núcleos de Pesquisa em Direitos Humanos e Cidadania LGBT (NUH/UFMG) e Psicologia Política (NPP/UFMG).

E-mail: mamprado@gmail.com 